\title{
Facultades y funcionamiento de la Suprema Corte de Justicia de los Estados Unidos de América
}

\section{Gómez Peralta, Héctor}

Facultades y funcionamiento de la Suprema Corte de Justicia de los Estados Unidos de América CIENCIA ergo-sum, vol. 25, núm. 3, noviembre 2018-febrero 2019 | e33 Universidad Autónoma del Estado de México, México

Esta obra está bajo una Licencia Creative Commons Atribución-NoComercial-SinDerivar 4.0 Internacional. 


\title{
Facultades y funcionamiento de la Suprema Corte de Justicia de los Estados Unidos de América
}

Powers and functioning of the Supreme Court of the United States of America

Héctor Gómez Peralta

Universidad Autónoma del Estado de Morelos, México

hgomezp1979@gmail.com

Recepción: 16 de octubre de 2016 Aprobación: 13 de septiembre de 2017

\section{Resumen:}

Se explica el funcionamiento interno y externo de la Suprema Corte de Estados Unidos. Además, se hace una revisión de sus facultades tanto jurídicas como políticas. Se utiliza una metodología neoinstitucional para analizar las reglas y aspectos formales, pero también las normas informales bajo las cuales se desenvuelven sus miembros. Los resultados muestran que, aun y cuando el presidente Donald Trump haya logrado que la Suprema Corte tenga en la actualidad una mayoría de magistrados conservadores, la institución tiene una dinámica propia que la convierte en un contrapeso bastante relevante sobre todo en dos de los temas más sensibles en la relación bilateral México-Estados Unidos: la migración y el comercio.

Palabras Clave: Poder judicial, Suprema Corte, sistema político de Estados Unidos.

\begin{abstract}
:
The article aims to explain the internal and external functioning of the Supreme Court of the United States, as well as to review its legal and political faculties. A neoinstitutional methodology is used, with which the rules and formal aspects are analyzed, but also the informal norms under which its members operate. The results show that even though President Donald Trump has achieved that the Supreme Court has currently a majority of conservative Justices, the latter has its own dynamics that make it a very important check and balance power, especially in two of the most sensitive issues in the US-Mexico relationship: migration and trade.
\end{abstract}

KEYWoRDs: Judicial Power, Supreme Court, American Political System.

\section{INTRODUCCIÓN}

Los estudios en México sobre el sistema político de Estados Unidos han sido sorprendentemente escasos. Esto a pesar de que casi todo lo que sucede en ese país tiene alguna repercusión en el nuestro. Estados Unidos es el principal socio comercial de México. Su influencia política y cultural sobre nosotros, junto con el resto del planeta, es innegable. Entender a Estados Unidos es entender a un actor crucial que contribuye, para bien o para mal, en la vida política de México.

En los trabajos académicos en lengua española sobre el sistema político de Estados Unidos (Casado, 2017; Soto, 2013; Toinet, 1994; Patricio, 1990; Chávez, 1994), la atención se centra en la presidencia, las elecciones, el Congreso, los medios de comunicación, los grupos de poder y su cultura política. Pero en dichos trabajos se ha descuidado de manera notable el estudio sobre el rol que tiene el Poder Judicial tanto en la vida sociopolítica como en la manera en que influye en los otros poderes, en especial en el Poder Ejecutivo. Cuando llegan a analizarse a las Cortes es usual que se haga desde una perspectiva eminentemente jurídica. Por eso este artículo, si bien busca explicar cómo funciona la Suprema Corte de Justicia de Estados Unidos, también pretende evidenciar su impacto dentro del sistema político nacional, sobre todo en lo relativo a cómo puede ser un contrapeso frente al poder presidencial, su rol en los procesos de democratización y su función como "creadora de legislación" (algo que sucede en mucho menor medida en los países regidos por tradiciones jurídicas de derecho romano y napoleónico, como México). 
El artículo está compuesto por tres secciones. En la primera se muestra cómo la Suprema Corte de Justicia tiene, dentro del sistema político de Estados Unidos, un protagonismo y unas facultades que hacen que sus sentencias, por las particularidades del sistema legal anglosajón, creen precedentes jurisprudenciales que van esculpiendo a la vida política, económica y hasta moral estadunidense por generaciones. En la segunda sección se busca contextualizar sobre los alcances que tiene la Suprema Corte dentro del federalismo del sistema estadunidense. Se explican los requisitos para que un asunto contencioso sea tratado por instancias federales y qué se necesita en particular para que la Suprema Corte acepte un caso. En la tercera sección se explica el funcionamiento interno de la Suprema Corte, así como los diversos escenarios o desenlaces en que puede devenir un juicio que esa institución ha atraído. Por último, se hace un ejercicio de prospectiva sobre el papel de la Suprema Corte ante las políticas de Donald Trump en materia comercial y migratoria.

\section{La Suprema Corte de Estados Unidos como Creadora de Legislación}

La Suprema Corte está integrada por nueve magistrados o jueces (Justices). Cada uno de ellos tiene el mismo peso que los demás al momento de votar sobre algún caso. Los magistrados, como todos los jueces federales, son propuestos por el presidente y ratificados por Senado. Como el resto de los jueces federales, sirven de por vida y únicamente pueden ser removidos de su cargo por incapacidad física o mental para desempeñar sus funciones o que ellos renuncien de manera voluntaria a su investidura. La Suprema Corte es el más alto tribunal legal en los Estados Unidos y trata temas concernientes al gobierno federal, disputas entre los Estados de la Unión y la interpretación de la Constitución. Ella puede declarar inconstitucional una acción hecha por el Legislativo o el Ejecutivo de cualquier nivel (federal, estatal o local) nulificando la ley y creando un precedente para futuras leyes y decisiones (Beard, 2006).

Si bien el texto constitucional se ha mantenido bastante estable a lo largo de los más de dos siglos de existencia del sistema político estadunidense, ${ }^{[1]}$ varias decisiones de la Suprema Corte han logrado que los artículos de la Constitución sufran diversas interpretaciones que terminan por darle una orientación distinta a dicho documento. Es común creer que el Poder Legislativo es el encargado de hacer las leyes, pero esto es sólo parcialmente correcto. Tanto el Congreso federal como los estatales hacen leyes que son llamadas estatutos (statutes). En la mayoría de las naciones occidentales los estatutos son el mayor y casi único cuerpo de leyes. Pero en Estados Unidos, así como en el Reino Unido y los países que forman parte de la Commonwealth, se rigen bajo el principio de la Ley Comn o Common Law, que consiste en que las decisiones del pasado que hayan emitido los tribunales influyen en las decisiones legales futuras (Morineau, 2001: 29-33).

El sistema se rige bajo el principio de stare decisis o "mantenerse con las cosas decididas". Es la idea de que una decisión de una Corte crea un precedente que restringe o impacta a las siguientes sentencias que se toman en ese mismo asunto o tema. En otras palabras, si una Corte emite un veredicto, todas las otras Cortes de la misma jurisdicción (estatal o federal, contenciosa o de apelación) tienen que aplicar el mismo criterio para emitir sus futuras sentencias, les agrade o no. El conjunto de todas esas decisiones judiciales es la Ley Comn.

Por eso, la Suprema Corte no solamente resuelve controversias, sino también provee de reglas jurídicas que resuelven problemas políticos y económicos específicos. Esto significa que las resoluciones de los jueces deben de tomar en cuenta las sentencias de los casos previos similares, al tiempo que se elevan a la categoría de precedentes (jurisprudencias) sus propias sentencias (Black's Law Dictionary, 2001: 1059).

Para ejemplificar lo políticamente relevantes que las sentencias de Suprema Corte pueden llegar a ser, se cita a uno de los casos más emblemáticos en la historia de Estados Unidos: Brow vs. Consejo de Educación (de 1954). En ese asunto la Suprema Corte estableció que era violatorio del principio de igualdad constitucional la segregación racial en las escuelas, por lo que prohibieron la separación entre colegios públicos de negros y de blancos. La sentencia propició que la niña afroamericana Linda Brown (quien interpuso la demanda) fuera admitida en una escuela donde hasta ese entonces sólo estudiaban blancos, sino que también se creó un precedente que tuvieron que tomar en cuenta el resto de las Cortes del país para resolver casos similares, lo 
que terminó por destruir la segregación racial en toda la nación. Es verdad que tardaron más de 15 años para que todo el sistema estadunidense se transformara en esa dirección, pero lo que se pretende resaltar en este artículo es el papel de los precedentes de la Suprema Corte como motor de profundos cambios políticos y sociales. A raíz de esa resolución de la Suprema Corte, las autoridades administrativas y legislativas de toda la nación, bajo la amenaza de ser demandadas judicialmente al realizar un acto de segregación, tuvieron que modificar sus políticas racistas de acuerdo con los cánones de integración que ordenó el Tribunal Supremo (Magaloni, 2008: 256).

\section{El rol de la Suprema Corte en la estructura federal del Poder Judicial de Estados Unidos}

Las Cortes están jerarquizadas, y la Suprema Corte está en la cima sobre las Cortes de primera instancia. Esto significa que cuando una Corte Menor (lower court) realiza una sentencia, ésta puede ser impugnada o apelada en una Corte Superior que puede reafirmar o anular las decisiones que emitió el tribunal inferior.

Los tribunales federales poseen el poder o la facultad para realizar revisiones judiciales (judicial review) tanto sobre las leyes que ha aprobado el congreso nacional como las de los congresos estatales. También pueden hacer revisiones judiciales sobre las acciones del presidente, por lo que pueden anular sus decretos $\mathrm{u}$ órdenes ejecutivas. Los jueces federales, a diferencia de los jueces de los tribunales estatales, tienen nombramientos vitalicios y sus salarios no pueden ser reducidos. Esto con el objetivo de preservar su independencia respecto a la política partidista y el juego electoral. La única manera de destituir a un magistrado es mediante el juicio político (impeachment), aunque muchas veces los jueces federales se retiran voluntariamente de sus cargos, sobre todo por vejez o enfermedad.

La jurisdicción original pertenece a los tribunales de primera instancia o Trial Courts. Al tener Estados Unidos 50 estados, existen 50 sistemas de tribunales o cortes, uno para cada estado de la Unión. Es por eso que la mayoría de los casos tienen lugar en las cortes estatales, no en las federales. De hecho, la mayoría de los casos no llegan a ningún tribunal, puesto que la inmensa mayoría de las disputas y litigios, penales o civiles, se arreglan fuera de las cortes. En el aspecto federal, los 94 tribunales de primera instancia se encuentran repartidos en los 11 distritos a lo largo del territorio de Estados Unidos. En la actualidad se cuenta con 663 jueces federales (ABA, 2016).

En algunos casos civiles, el demandante, la persona (física o moral) que inicia la disputa legal tiene la opción de elegir si su caso será tratado por un tribunal estatal o uno federal. Los casos criminales empiezan casi siempre en las cortes estatales. Si uno de los implicados no está de acuerdo con el resultado del juicio y tiene argumentos razonables para impugnar el procedimiento de dicho juicio (como la conducta sesgada o inapropiada del juez), se tiene la posibilidad de llevar el caso a un tribunal de apelaciones. Si alguien inicia un litigio en las cortes estatales, llega a tener más oportunidades para apelar o impugnar la sentencia debido a que la mayoría de los estados tienen dos niveles de cortes de apelación, más la Corte de Apelación Federal (USCourts, 2016).

Pero las cortes de apelación no aceptan todas las impugnaciones que les presentan, sino que tienen el poder de desestimar o rechazar una solicitud de apelación. En ese caso el inconforme no tiene más opción que $s$ ujetarse a lo dispuesto por la sentencia original. Esto se debe a que los perdedores de un juicio casi siempre van a sentirse inconformes y tratarán de apelar o impugnar el fallo. Esto aplica incluso si el perdedor del juicio es la procuraduría o fiscalía que falló al tratar de armar un caso y comprobar la culpabilidad de alguien.

Las Cortes de Apelación Federales son también llamadas Cortes de Circuito y son 12 en total, distribuidas regionalmente a través de todo el territorio de la Unión Americana. El lugar en el que se lleve a cabo un juicio puede ser muy relevante para su resultado. Por ejemplo, los jueces del Noveno Circuito, que incluyen a Oregón y California (bastiones electorales del partido demócrata), tienden a ser más liberales que los jueces 
del Quinto Circuito, donde están estados que lucharon por mantener la esclavitud en la Guerra Civil y son "voto duro" del conservador partido republicano (USCourts, 2016).

Normalmente las apelaciones en el ámbito federal son atendidas por paneles de tres jueces, mientras que los juicios en los tribunales de distrito son presididos por un juez. Pero además de recibir apelaciones, existen cinco escenarios en los cuales una Corte federal tiene jurisdicción original, es decir, que es de su competencia primaria atender esos casos. Son los siguientes:

a) Casos donde la ley en cuestión sea una ley federal, como las quejas contra la ley de deportaciones.

b) Casos que involucren tratados internacionales o gobiernos extranjeros.

c) Casos que involucren a la Constitución de los Estados Unidos, como podría ser una demanda donde alguien alegue una violación a su libertad religiosa o a portar armas de fuego.

d) Casos donde el gobierno federal sea una de las partes en litigio (ya sea como demandado o como demandante).

e) Casos donde esté involucrado más de un estado de la Unión y estén involucrados más de 70000 dólares (FJC, 2016).

Sin embargo, las decisiones que más llaman la atención de los medios de comunicación, juristas, científicos sociales, e incluso pueden llegar a ser parte de los libros de historia, son las de la Suprema Corte de Justicia de los Estados Unidos. La Suprema Corte es un tribunal de última instancia, es decir, sus decisiones son inapelables. Para que un caso llegue a la Suprema Corte es porque previamente se pasó por una Corte de Apelación Federal. Aun así, existen ciertas circunstancias bajo las cuales ese Tribunal Supremo tiene jurisdicción original y funciona como un Trial Court: ${ }^{[2]}$

a) Casos de disputa entre el gobierno federal contra alguno o algunos estados de la Unión.

b) Casos de disputa entre dos o más estados de la Unión.

c) Casos que involucren a funcionarios extranjeros o embajadores.

d) Casos entre uno o más ciudadanos de un estado contra uno o más ciudadanos de otro estado o contra algún país extranjero.

e) Crímenes cometidos en alta mar, donde ningún estado tiene jurisdicción (Black, 1960: 22).

Cada año la Suprema Corte recibe entre 8000 y 10000 solicitudes de casos para ser atendidos, pero sólo acepta entre 70 y 90 casos al año (Hall, 2005: 24). Esto es posible gracias a que la Suprema Corte ha establecido un conjunto de "filtros" para admitir casos, llamados reglas de decisión. Son las siguientes:

a) No se le puede pedir a la Suprema Corte que revise si una ley es o no constitucional si no ha existido previamente un efecto. Primero debe de haber algún daño existente, no hipotético o con probabilidad de ocurrir a futuro, causado por dicha ley. Dicho de otro modo, la Suprema Corte no es una consejera o emite opiniones sobre ciertos temas especulando sobre algo que puede o no suceder.

b) El litigio debe de contar con presencia del perjudicado (standing). Para que se acepte tomar un caso, las partes involucradas deben de tener una participación sustancial en el resultado del juicio, como puede ser un daño en su persona o su propiedad. La falta de standing de un caso es el motivo más usual por el que la Suprema Corte se ha negado a atraer casos como el del matrimonio entre personas del mismo sexo, ya que su impugnación es presentada por gente que no está casada con alguien de su mismo sexo, por lo que si existe un daño, no es sobre aquel que presenta la demanda.

c) El caso debe de tener relevancia práctica (mootness). Esto significa que sólo se atienden casos si el demandante todavía necesita una resolución. Por ejemplo, si el quejoso muere, el caso es rechazado. También se excluyen casos donde el daño es sólo potencial, es decir, que todavía no ocurre (ripeness).

d) Doctrina de cuestión política. En muchos casos, la Suprema Corte prefiere dejar que el Ejecutivo o el Legislativo sean quienes atiendan los problemas sobre todo si la disputa gira en torno a asuntos que los otros poderes podrían atender por sí mismos (Hall, 2005: 87). 
Pero existen ciertos casos que la Suprema Corte casi siempre acepta tratar: tal es el caso de cuando se presenta un conflicto de circuito (circuit split), que es cuando los Tribunales de Circuito han emitido resoluciones diferentes o contrapuestas sobre el mismo tema. La Suprema Corte casi siempre toma esos casos para resolver la confusión y fijar con claridad y certeza cuál será el precedente o jurisprudencia que prevalecerá. Asimismo, la Suprema Corte casi nunca rechaza tomar un caso solicitado por el gobierno federal o si hay una evidente disputa constitucional, como sería una demanda que involucre la libertad de expresión o una violación al debido proceso (due process) (Garro, 1992: 85-95). Pero equé es lo que sucede una vez que un caso llega a manos de la Suprema Corte?

\section{El funcionamiento interno de la Suprema Corte de Justicia de Estados Unidos}

Varias peticiones formales se presentan ante la Suprema Corte, pero no es garantía de que serán aceptadas. El Solicitador General (miembro del Departamento de Justicia), que es la persona designada para representar al gobierno federal ante la Suprema Corte, determina la posición legal que los Estados Unidos tendrán en dicho Tribunal. Ese funcionario rechaza muchas de las peticiones para ser atraídas por la Suprema Corte debido a que esos casos no involucran leyes federales o porque esas controversias ya han sido decididas en otros casos. Si la petición es aceptada en esta instancia, se canaliza a la junta de respuesta (cert pool), donde los jueces deciden qué casos van a juzgar y cuáles no (Thompson, 2009: 258-259). Para que una solicitud sea aceptada, al menos cuatro de los nueve jueces deben de estar de acuerdo en ello, motivo por el cual a esto se le conoce como la regla de cuatro. Al debate sobre qué solicitudes serán aceptadas se le conoce como la conferencia.

Si el caso solicitado pasa este nuevo filtro, las partes en disputa tienen que presentar un escrito legal (brief) donde cada una argumente por qué la Constitución y las leyes favorecen su posición. Aquel que presenta el caso buscando invalidar una decisión de una Corte de instancia anterior es conocido como el solicitante o demandante (petitioner). En contraparte, quien busca mantener o reafirmar la sentencia citada es el demandado o acusado (respondent). El demandante también incluye en su escrito o brief una argumentación contra la posición del demandado (Thompson, 2009: 265).

En muchos casos existen individuos o grupos que no son alguna de las partes en litigio, pero tienen interés en el resultado del juicio. Tal es el caso de una iglesia en un juicio sobre el derecho de los médicos a negarse a practicar un aborto, o de una ONG (organización no gubernamental) o una empresa sobre un juicio sobre libertad de expresión, por citar sólo un par de ejemplos. Estos actores también pueden presentar escritos ante la Suprema Corte que contengan argumentos legales, económicos o históricos que puedan persuadir a los jueces para fallar a favor de sus intereses u opiniones. Esto también puede ser una vía para que los grupos de interés intenten incidir en la Suprema Corte.

Una vez que son archivados todos los escritos indicados, la Suprema Corte agenda una serie de sesiones para que las partes en litigio hagan argumentaciones orales. Cada parte tiene hora y media para presentar su caso ante los jueces, pero estos también pueden hacer preguntas. En los hechos, la mayor parte del tiempo se gasta en que las partes en disputa respondan a los cuestionamientos de los magistrados. Posteriormente los jueces se juntan para otra conferencia (por lo regular en miércoles o viernes) donde debaten entre ellos sobre los argumentos escritos y orales.

Para que la Suprema Corte emita una sentencia o decisión oficial, una mayoría de jueces, al menos cinco de nueve, debe de apoyar con su voto alguna de las posiciones en disputa. Pero también pueden decidir regresar o r emitir (remand) el caso a una Corte de instancia inferior para una nueva sentencia (Thompson, 2009: 295).

El Presidente de la Suprema Corte (Chief of Justice) ${ }^{[3]}$ dirige tanto las conferencias como las audiencias, además de la redacción del documento donde se plasma la sentencia de la Suprema Corte. En ocasiones la Suprema Corte emite una opinión mayoritaria, que es un sólido y contundente acuerdo por parte de todos los magistrados. En el histórico caso sobre derechos civiles que se citó anteriormente, Brown vs. Consejo de 
Educación (Board of Education), la Suprema Corte emitió una resolución incluso más fuerte que la opinión mayoritaria, una opinión unánime.

En otras ocasiones la Suprema Corte emite múltiples opiniones de un mismo caso. La decisión de confirmar o anular una sentencia de un tribunal de instancia inferior es nombrada el dictamen (bolding). En cada dictamen se expone un razonamiento legal (rationale). Si uno o más jueces están de acuerdo con la opinión mayoritaria del dictamen, pero lo hacen por razones legales diferentes a la del resto de sus pares, escriben una opinión concurrente (concurring opinion), que es una sentencia para el caso en disputa, pero que los tribunales inferiores no están obligados a seguir. Es decir, no genera jurisprudencia. Sólo los dictámenes con razonamiento legal por opinión mayoritaria o unánime crean jurisprudencia o precedente jurídico que debe de ser adoptado por las Cortes inferiores (Ledebur, 2009: 903-904).

La inmensa mayoría de los dictámenes de la Suprema Corte no son unánimes debido a que los jueces están divididos ideológicamente entre liberales y conservadores. Los magistrados que perdieron la votación en la decisión de una sentencia pueden escribir una opinión disidente (dissenting opinion), la cual obviamente no crea precedente jurisprudencial alguno para las Cortes inferiores ni tiene la obligatoriedad de la ley. Pero algunas veces esas disensiones están redactadas de forma tan elocuente que llegan a ser usadas para formular argumentos legales que pueden persuadir a futuros miembros de la Suprema Corte en decisiones similares. En el caso de Plessy vs. Ferguson (1896), la Suprema Corte decidió que la segregación racial era constitucional. Esa sentencia, ganada siete votos a uno (sólo hubo ocho votos porque un juez no participó en la decisión), fue el pilar de la doctrina "separados pero iguales" que consistía en la separación de miembros de grupos de raza blanca de otros grupos étnicos en escuelas, cines, transporte público, baños, vecindarios, etcétera. La opinión disidente de ese caso, la del juez John Marshall Harlan que perdió la votación, tuvo tal impacto en los jueces de la Suprema Corte de generaciones posteriores que terminó por convertirse en la opinión unánime de un caso futuro (el juicio Brown vs. Consejo de Educación) si bien tuvieron que pasar 50 años para que eso sucediera (Tushnet, 2008: 69-80).

La Suprema Corte tiene, además de un poder jurídico, un poder político mucho más alto que cualquiera de las Cortes de los países considerados democráticos. Al igual que el presidente de la república, conforme la Suprema Corte ha aumentado su protagonismo en el sistema político, ha sido objeto de múltiples críticas. La principal de ellas señala que si bien los Padres Fundadores dotaron a la Suprema Corte de puestos vitalicios y sus salarios no pueden ser reducidos, con la intención de darle a sus miembros independencia y libertad para la toma de sus decisiones, la combinación de magistrados de edad avanzada con puestos de por vida en una era donde los seres humanos vivimos casi el doble que hace 200 años produce que un miembro de la Suprema Corte represente las perspectivas y valores de las generaciones pasadas en lugar de las visiones de la actual sociedad (Abraham, 1992: 142). También resulta irónico que un cuerpo muy pequeño de "sabios" o "notables", que son política y electoralmente irresponsables, como lo son los miembros de la Suprema Corte, en la práctica ejerce un inmenso poder dentro de un sistema que se considera a sí mismo un modelo de democracia.

\section{EpÍlogo: la Suprema Corte en Migración y COMErCio DURANTE LA ERA Trump}

Haciendo un ejercicio de prospectiva, importantes actores y sectores en México han centrado su atención sobre el futuro de sus relaciones comerciales y migratorias con Estados Unidos en lo relativo a su presidente recién electo, Donald Trump. Pero la Suprema Corte jugará sin duda un rol crucial al respecto. El mayor poder que tiene la Suprema Corte es su facultad para invalidar leyes y acciones tanto del Ejecutivo como del Legislativo, al declararlas inconstitucionales (Judicial Review). Muchas de las acciones que Trump emprendiera y que podrían afectar a México podrían revertirse mediante impugnaciones judiciales si bien tendrían que ser iniciadas por ciudadanos, legisladores o gobernadores estadunidenses. 
La Suprema Corte de Estados Unidos tiene y seguirá teniendo un papel crucial en muchos temas que afectan directa o indirectamente a México, de manera especial durante la actual administración de Donald Trump donde varias acciones por parte del Ejecutivo de esa nación pueden cambiar las relaciones comerciales y migratorias entre ambos países. Los puntos de mayor tensión y donde la Suprema Corte de Estados Unidos puede ser un actor clave son las negociaciones del Tratado de Libre Comercio de América del Norte (TLCAN), las deportaciones masivas y la derogación de programas de amnistía o ayuda a migrantes ilegales como el DACA. ${ }^{[4]}$

La postura que tendrá la Suprema Corte en temas migratorios durante la era Trump puede vislumbrarse al analizar la manera en que el Poder Judicial de Estados Unidos ha actuado desde el principio de la actual administración sobre ese mismo asunto. Es el caso del congelamiento de la Orden Ejecutiva que el presidente Donald Trump emitió para negar el acceso a territorio estadunidense a migrantes provenientes de varios países con población mayoritariamente musulmana aunque contaran con una visa vigente. El argumento que dio el presidente para dicha acción fue que ellos representaban un peligro para la seguridad nacional. El velar por la seguridad nacional es un ámbito de competencia del Poder Ejecutivo. Sin embargo, la Corte de Apelaciones del Noveno Circuito de Estados Unidos rechazó la justificación legal de la Orden Ejecutiva, con lo que suspendieron la acción del presidente argumentando que lo que Trump había hecho era una acción considerada discriminatoria. La administración de Trump nunca pudo probar ante los jueces federales que los migrantes a los que se les negaba el acceso a Estados Unidos podían cometer actos terroristas. Esa decisión judicial fue de suma importancia. Ocasionó que el veto migratorio de Trump durara solamente 120 días y, en ciertos casos, según el país de procedencia, 90 días.

Lo anterior es una muestra de cómo el Poder Judicial de Estados Unidos puede fungir como dique ante las decisiones emitidas por el presidente, pero el resultado cambia según el tema en cuestión. Por ejemplo, casi inmediatamente después de que Donald Trump diera por terminado a inicios del 2017 el programa DACA, donde dejó en un limbo legal a más de 800000 migrantes, $75 \%$ de los cuales son mexicanos, los fiscales de varios estados de esa nación iniciaron procesos legales para impedir el fin de la amnistía migratoria que fue otorgada por el entonces presidente Barack Obama. El argumento de Trump para suspender DACA es que la Orden Ejecutiva emitida por Obama era inconstitucional. ¿Cuál podría ser el fallo de la Suprema Corte en este caso? La respuesta puede encontrarse en la manera en que la Suprema Corte se pronunció con DAPA, el programa hermano del DACA. ${ }^{[5]}$

En 2014, casi inmediatamente después del anuncio del DAPA, 25 estados (23 de ellos gobernados por el partido republicano) impugnaron la constitucionalidad de la Orden Ejecutiva de Obama, por lo que en 2015 un tribunal de Texas suspendió al DAPA. El gobierno de Obama apeló en los tribunales federales la decisión, pero la Corte de Apelaciones del Quinto Circuito validó la decisión del tribunal texano. La Casa Blanca llevó el caso hasta la Suprema Corte, el cual tomó en 2016. En esa ocasión hubo un empate de votación al respecto ( 4 a 4) debido a que en ese momento solamente había 8 jueces. ${ }^{[6]}$ Esa anomalía se debía a que había fallecido el juez Antonin Scalia y el Senado no había logrado el consenso suficiente como para nombrar a uno de los nominados por Obama para ocupar la vacante. Ante ese empate, quedó vigente la decisión del tribunal de a pelación, es decir, el DAPA murió en los tribunales.

Ahora que Donald Trump logró que su nominado Neil Gorsuch fuera validado por la Cámara Alta del Congreso como el noveno miembro de la Suprema Corte, inclinando la balanza del lado de los jueces conservadores, las probabilidades de que la constitucionalidad del DACA sea validada son bajas. Aunque siempre existe la posibilidad de que algún juez cambie de opinión, muy rara vez ocurre.

Respecto al TLCAN, para saber si Trump podría o no terminar con ese tratado de forma unilateral es necesario revisar lo que la Suprema Corte de Estados Unidos ha fallado al respecto. Según la Constitución de ese país, el Poder Ejecutivo es el principal actor negociador y portavoz de los intereses de Estados Unidos ante otras naciones. Pero la Suprema Corte ha estipulado en varias ocasiones que eso no significa que el presidente 
dicte por sí sólo la política ni la agenda internacional. Las cláusulas comerciales son precisamente uno de los mayores puntos débiles de la institución presidencial.

La Constitución estipula con claridad y sin lugar a dudas que el Ejecutivo no puede hacer tratados por sí mismo, sino que necesita de la aprobación del Congreso. Pero la Constitución no dice nada sobre el proceso para terminar con dichos tratados. Es justo en este tipo de situaciones donde la Suprema Corte interpreta la Constitución y estipula qué puede y qué no puede el Ejecutivo. En los medios tanto de México como de Estados Unidos existe un debate sobre si el Presidente puede o no terminar con dichos tratados sin el visto bueno del legislativo. ¿Quién está en lo correcto?

La Suprema Corte en varias ocasiones se ha pronunciado al respecto. En 1994, el caso de Barclays vs. California, la Corte estipuló que "la Constitución expresamente le otorga al Congreso, no al presidente, la facultad de regular el comercio con naciones extranjeras" (Supreme Court, 2017). Bajo esa premisa, si Trump rompiera el TLCAN sin la aprobación del Congreso, estaría imponiendo regulaciones al comercio, lo que daría pie para toda una serie de disputas legales en contra de dicha decisión, en la cual la más severa de ellas sería la "usurpación de poderes".

En muchas otras ocasiones la Suprema Corte se ha negado a considerar que el Ejecutivo tiene la facultad para terminar tratados o imponer regulaciones internacionales de forma independiente o unilateral, como es el caso en Goldwater vs. Carter en 1979 o de Zivotofsky vs. Clinton en el 2012. Si Trump terminara el TLCAN sin la aprobación del legislativo, los exportadores, consumidores e incluso los miembros del Congreso de Estados Unidos muy seguramente demandarán al presidente, con lo que sería la Suprema Corte quien tendría que dar un fallo al respecto, la cual históricamente ha defendido la tesis constitucional de que es el Congreso, no el presidente, el decisor de última instancia en materia comercial. El problema es que, como se ha visto a lo largo de este artículo, el camino en las Cortes es largo. Mientras el asunto se debate en los tribunales (y puede durar años), la incertidumbre invariablemente tendría un efecto adverso para la economía mexicana, aun y si al final la Suprema Corte terminara anulando la decisión del presidente.

\section{REFERENCIAS}

ABA. (2016). How the legal system works: The structure of the Court System, State and Federal Courts. Disponible en http://litigation.findlaw.com/legal-system/what-sorts-of-cases-do-state-courts-decide.html. Consultado el 07-09-2016.

Abraham, H. (1992). Justices and presidents: Apolitical history of appointments to the Supreme Court. New York: Oxford University Press.

Beard, A. (2006). The Supreme Court and the Constitution. New York: Dover Publications.

Black, L. (1960). The people and the Court. New York: MacMillan.

Black's Law Dictionary. (2001). Stare Decisis. St. Paul Minn: West Group.

Casado, Y. (2017). El sistema politico de Estados Unidos. Madrid: Editorial Tecnos.

Chávez, A. (1994). Presidencialismo y sistema político: México y los Estados Unidos. México: Fondo de Cultura Económica.

FJC (Federal Judicial Center) (2016). Federal Courts and what they do. Disponible en http://www.fjc.gov/public/pd f.nsf/lookup/FCtsWhat.pdf/\$file/FCtsWhat.pdf. Consultado el 6 de septiembre de 2016.

Garro, A. M. (1992). Algunas reflexiones sobre la Corte Suprema de los Estados Unidos en su actual composición y el rol institucional de la Corte. Revista Española de Derecho Constitucional, 35, 85-95.

Hall, L., (2005). The Oxford Companion to the Supreme Court of the United States. New York: Oxford University Press. Ledebur L. (2009), Plurality rule, concurring opinion and a divided Supreme Court. Disponible en http://pennstatela 
Magaloni, A. L. (2008). El poder judicial, en R. Fernández de Castro y H. Blackmore (Coords).¿Quées Estados Unidos? México: Fondo de Cultura Económica.

Morineau, M. (2001). Introducción al common law. México: Universidad Nacional Autónoma de México.

Patricio, M. (1990). El sistema político de los Estados Unidos de Norteamérica. México: Universidad Nacional Autónoma de México.

Soto, A. (2013). Sistema constitucional y politico de los Estados Unidos de América. México: Porrúa.

Supreme Court (2017). Barklays Bank PLC vs. Franchise Tax Bd. Of California. Disponible en https://supreme.just ia.com/cases/federal/us/512/298/. Consultado el 11 de septiembre de 2017.

Thompson, D. (2009). An empirical analysis of Supreme Court certiorari petition procedures. George Mason University Law Review, 16(2), 237-241

Toinet, M. (1994). El Sistema politico de los Estados Unidos. Madrid: Fondo de Cultura Económica.

Tushnet, M. (2008). I dissent: Great opposing opinions in landmark Supreme Court Cases. Boston: Beacon Press.

USCourts. (2016). Court Role and Structure. Disponible en http://www.uscourts.gov/about-federal-courts/court-ro le-and-structure. Consultado el 5 de septiembre de 2016.

\section{Notas}

[1] Se dejan a un lado las diez primeras enmiendas, ya que formaron parte del proceso de promulgación de la Constitución entre 1789 y 1791, desde entonces sólo ha habido 17 enmiendas a la Carta Magna de Estados Unidos. En contraste, en México ha habido 699 cambios constitucionales en la mitad de tiempo.

[2] Es por ello que los magistrados tienen que ser abogados, a pesar de que la Constitución no establece ese requisito para ser miembro de la Suprema Corte.

[3] El presidente de la Suprema Corte es uno de los nueve jueces que integran a ese tribunal supremo. Si bien preside las sesiones de la Corte, no posee algún tipo de voto preferencial o poderes para instruir a alguno de los demás ministros. El c a rgo se obtiene al ser nominado por el presidente y confirmado por el Senado.

[4] La Acción Diferida para los Llegados en la Infancia o DACA (Deferred Action for Childhood Arrivals) es un programa que permite que inmigrantes ilegales que fueron llevados por sus padres a Estados Unidos a corta edad, por lo que no estaban violando las leyes migratorias conscientemente, puedan recibir licencias de conducir, trabajos temporales y un número de seguridad social con lo que podrían, entre otras cosas, ingresar a instituciones de educación superior a pesar de su estatus migratorio.

[5] El Programa de Acción Diferida para los Padres o DAPA (Deferred Action for Parents of Americans) fue una política de amnistía emitida en 2014 por Barack Obama que amparaba contra la deportación de millones de indocumentados que son padres de ciudadanos o residentes legales de Estados Unidos.

[6] La Suprema Corte históricamente ha estado dividida de manera ideológica, manteniendo cierto equilibro entre posturas liberales y otras conservadoras. Antes de la llegada de Trump en la presidencia, la Corte tenía a cuatro de sus magistrados (justices) con tendencias "liberales" (Ruth Bader, Stephen Breyer, Sonia Sotomayor y Elena Kagan), tres conservadores (Clarence Thomas -un afroamericano considerado el miembro más conservador de la Corte-, John Roberts y Samuel Alito) y uno más cuyo voto oscila (swing vote) entre ambas posturas (Anthony Kennedy), quien para el caso del DAPA votó por declararla inconstitucional. Trump logró que el sustituto de Scalia fuera el conservador Neil Gorsuch, con lo que el número actual de conservadores es de cuatro. El protagonismo que tiene la Suprema Corte en el sistema político de Estados Unidos es el motivo por el cual la nominación y selección de sus magistrados es un asunto extremadamente controversial y debatido. Un presidente liberal tratará de colocar a un magistrado con valores similares, y de igual modo con un presidente que simpatice con el pensamiento conservador debido a que los puestos de magistrados comúnmente sólo se cubren conforme estos van falleciendo o enfermándose a tal grado que no pueden cumplir con sus funciones. Un presidente de Estados Unidos en el tiempo que dura su administración sólo puede influir en el nombramiento de uno o dos magistrados de la Suprema Corte, por lo que existe cierto equilibro en el pleno de ese organismo entre las diferentes posiciones ideológicas de la sociedad norteamericana (Abraham, 1992).

\section{BY-NC-ND}

